\title{
Analysis of Water Pollution in Coastal Waters
}

\author{
Dr. S. K. Sharma \\ Department of Physics, N.A.S. College, Meerut, India
}

\begin{abstract}
Water pollution is a problem of serious environmental issue in India as its 70 percent surface and groundwater resources contaminated by various pollutants such as biological, toxic, organic, and inorganic. Among all the largest source of water pollution in India is untreated sewage. Agricultural runoff and unregulated small-scale industry are the other sources of pollution. Most of the rivers, lakes and surface water in our country are polluted due to industries, untreated sewage and solid wastes. The outcome of this mammoth problem is the rising socio-economic cost of poor water quality.Almost 40 million litres of wastewater enters rivers and other water bodiesevery day with a very small fraction of it being adequately treated. The most badly hit class due to water pollution is the weaker sections of the society as these people mostly resides near main water bodies in India. According to the World Bank report such releases of pollution in the up streams reduces the economic growth in the downstream areas, which reduces the growth of GDP in these regionswhich create a downward impact on the overall GDP of the country. Almost half of the GDP is lost. Due to the polluted stretches in India the agricultural revenues decreases to $9 \%$ andalso a $16 \%$ fall in agricultural yields downstream areas. Some remedial measures should be adopted to protect the poor masses of the country. Water pollution near oceans, rivers, lakes should be controlled. Waste ingredients should not be disposed in oceans, rivers, lakes and ground water. Controlled use of pesticides and fertilisers should be done as this will prevent runoffs of the material into nearby water sources.Clean water bodies will result in the sustained development of the country particularly the vulnerable sections of the society. It is the dire need of the hour to control water pollution to achieve the vision of the healthy nation'.
\end{abstract}

Keywords: Water Pollution, Unregulated Small Scale Industries, Waste ingredients, Vulnerable Sections

\section{Introduction}

Water pollution is a major environmental issue in Indiaas its 70 percent surface and groundwater resources contaminated by various pollutants such as biological, toxic, organic, and inorganic. Among all the largest source of water pollution in India is untreated sewage. Agricultural runoff and unregulated small-scale industry are the other sources of pollution. Most of the rivers, lakes and surface water in our country are polluted due to industries, untreated sewage and solid wastes.

Water pollution is the major cause of many hazardous diseases in India. The harmful consequences of the polluted water not only affect the life of present generation but it also affects the life of upcoming generations because its effect remains for long. Bhopal gas tragedy case is a biggest example. Bhopal Gas tragedy is the world's worst industrial disaster. Various studies by official scientific agencies reveals that ground water contamination has spread upto40 meters deep and upto $3.5 \mathrm{~km}$ from the abandoned factory in Bhopal. This contaminated water was consumed by nearly 40000 persons over the past 14 to 20 years and cancers, birth defects and diseases related to skin, lungs, brain, kidneys and liver are several times more prevalent in that community than any other place in the country. There are multifold uses of water. It is impossible for the human being to survive without the water. Human being cannot live without the water. Pure and pollution free water is indispensable for a healthy life. If water is polluted in any particular area, then people or the other living creatures are forced to drink that polluted water due to unavailability of any other option nor can they live without it. Water pollution has become a serious problem across the country in recent years mostly due to the presence of untreated effluents, chemicals and pesticides in it.Discharge of untreated sewage is the most important source of pollution of surface and ground water in India. The problem is not only that India lacks sufficient treatment capacity but also that the sewage treatment plants that exist do not operate and are not maintained.

The majority of the government-owned sewage treatment plants remain closed most of the time due to improper design or poor maintenance or lack of reliable electricity supply to operate the plants, together with absentee employees and poor management. The waste water generated in these areas normally percolates into the soil or evaporates. The uncollected waste accumulates in the urban areas causing unhygienic conditions and releasing pollutants that leach into surface and groundwater. According to a report, 114 Indian cities were dumping untreated sewage and partially cremated bodies directly into the Ganges River. Lack of toilets and sanitation facilities causes open defecation in rural and urban pill areas of India and became a source of surface water pollution. The present article is based on the secondary data collected. The study area covered under the article was the low lying areas of the river banks of the Northern India.

\section{Clean Water Accessibility:}

Right to access clean water is the basic human right of a person as it is the basic need of the human being and is also one of the main substances for the survival of human being. In daily life water has multifunctional role. It is used for drinking, bathing, cleaning and irrigation etc. The major water bodies from where people access water are lakes, rivers, oceans, ponds and groundwater. People also get water from the State also. On July 28, 2010 UN General Assembly passed a resolution to make water and sanitation as right. The Government of India is the trustee of all natural resources which are meant for public use and enjoyment by nature and water is such one of the naturalresources. The Constitution of India under article 15 (2)(b) provides the right that water is accessible for all irrespective of caste and religion. 


\section{Causes of Water Pollution:}

The term water pollution can be defined in many ways. Rendering the water unfit for human consumption by having changes in its natural quality is known as water pollution. It can also be defined as when one or more substances have contaminated water to such an extent that they cause problems for people and animals. Water Pollutants includes a wide range of chemicals, micro organisms and physical chemistry etc. Most of the chemical substances are toxic. Micro organisms availablein water can produce waterborne diseases. The main causes of water pollution are:

\section{1) Downstream untreated sewage:}

The predominant cause of water pollution in India is sewage discharged from cities, towns and some villages. According to a report of the World Health Organization out of India's 3,119 towns and cities, just 209 have partial sewage treatment facilities, and only 8 have full wastewater treatment facilities. The polluted and untreated water in the downstream areas is used for drinking, bathing, and washing. It was claimed that 114 Indian cities were dumping untreated sewage and partially cremated bodies directly into the Ganges Rivermakin it worstly polluted. causes open defecation in rural and urban due to lack of toilets and sanitation facilities pill areas of India. This is a major source of surface water pollution. Investment is needed to bridge the gap between sewage generated in India and its treatment capacity of sewage per day. Major cities of India produce 38,354 million litres per day (MLD) of sewage, but the urban sewage treatment capacity is only 11,786 MLD. A large number of Indian rivers are severely polluted as a result of discharge of domestic sewage.From a scientific analysis of water samples from 1995 to 2018 indicates that the organic and bacterial contamination is severe in water bodies of India which is mainly due to discharge of domestic waste water in untreated form, mostly from the urban areas of India.Approximately 638 million people in India defecate in the open, and 67 per cent of Indian households do not treat their drinking water.

\section{2) Presence of Organic matter:}

The water quality monitoring was done in the year 2010. It was found that almost all rivers were with high levels of BOD (a measure of pollution with organic matter). In decreasing order, the worst pollution were found in river Markanda (490 mg/l BOD), followed by river Kali (364), river Amlakhadi (353), Yamuna canal (247), river Yamuna at Delhi (70) and river Betwa (58). For context, a water sample with a 5-day BOD between 1 and $2 \mathrm{mg} \mathrm{O} / \mathrm{L}$ indicates a very clean water, 3 to $8 \mathrm{mg}$ $\mathrm{O} / \mathrm{L}$ indicates a moderately clean water, 8 to 20 indicates borderline water, and greater than $20 \mathrm{mg} \mathrm{O} / \mathrm{L}$ indicates ecologically-unsafe, polluted water.Near the cities and towns, the levels of BOD are found severe but in rural areas of India, the river BOD levels are sufficient to support aquatic life.

\section{3) Level of Coliform:}

The most coliform polluted water bodies in India are rivers, Yamuna, Ganga, Gomti, Ghaghara, Chambal, Mahi, Vardha and Godavari. The amount of coliform must be below $104 \mathrm{MPN} / 100 \mathrm{ml}$. If it is preferably absent from water then it is considered safe for general human use, and for irrigation where coliform may cause disease outbreak from contaminated-water in agriculture.

\section{4) Industrialisation:}

Industrial waste adds water pollution to the water bodies. The industrial waste is toxic to the life forms that consume this water. The thermal power plants are the largest pollution creating industry followed by electroplating units, paper mills, steel plants, textile and sugar industries. Other large scale and small scale and cottage industries also contribute their share of water pollution. There are around 3 million small and cottage industries in India. They do not have proper pollutant disposal systems but then also adopt polluting production technologies like use of dyes in fabrics, cadmium in ornaments, chrome in tanning leather and other toxic chemicals etc. The waste of these industries get scattered around or dumpedand effluents flow through drains or percolates or get washed away during the next rainy season and pollutes the downstream areas.

5) Agricultural malpractices:

At the onset of the monsoons, the fertilizers and the pesticides are washed into the nearest water bodies. According to a senior scientist, A.K. Dikshit from Indian Agricultural Research Institute (IARI), New Delhi, Indian farmers are mostly engaged in over usage of fertilizers and pesticides. More doses pollute water, air and land.

6) Religious and Social Practises:

Religious and social practisesamong the Indians also increase the water pollution in our rivers. As a matter of religious faith carcasses of cattle and other animals are disposed in the rivers, dead bodies are cremated on the banks of the rivers. As a matter of ancient rituals, partially bodies are flung into the rivers which adversely affect the water quality of the rivers. Another environmentally harmful practice is the mass bathing in a river during the religious festivals. Due to this 'holy dip' the biochemical oxygen demand (BOD) goes up drastically. Offerings from 'puja' are also immersed in the rivers. People immerse these offerings in plastic bags making situation worst.

\section{Impact of Water Pollution}

Water pollution is a global problemand has reached a dangerous mark in India. Rivers are the main victims of excessive water pollution. Approximately $70 \%$ of the surface water is unfit for consumption in India. The impact of water pollution is:

\section{1) Loss to Flora and Fauna}

Water contamination is threatening biospheres and ecosystem. Chemicals, effluents and sewage is causing the species of aquatic life to extinct or to migrate. Migratory birds shun the rivers and as a result face extinction. The existence of many species of flora and fauna are threatened due to rising pollution in India.

\section{2) Impact on Livelihood}

Indian water banks were once flourished with fish farms and fisherman. They are finding it difficult to catch edible fishes. Fishes from polluted water are found to be contaminated with mercury, lead and cadmium and thus found to be unfit for human consumption. Edible fishes are found infected with Salmonella, Shigella and other 
harmful microbes found in human faeces which are harmful for consumption.

3) Waterborne and Water-washed Diseases

Due to rising pollution in water bodies, approximately two-thirds of the Indian masses do not get safe and clean drinking water which increases the risk of waterborne diseases. Diarrhoea is the one of the largest killer disease in India caused due to water pollution. According to a report of NitiAayog, whopping 200,000 people losses their lives every year due to consuming polluted water. The health hazards due to infected water ranges from cancer to gastrointestinal disorders, depletion of calcium from bonesof humans and animals ( Osteoporosis), impotence among men, tuberculosis, sterility among women and other severe diseases. Water-washed diseases as skin and eye infection are caused due to lack of clean water.

4) Makes water Hard

The TDSlevel of water increases due to excessive amount of pollution which makes it hard. The TDS level of water rises as water is a good solvent and it picks up the impurities easily. Total Dissolved Solids (TDS) consists of inorganic salts as calcium, magnesium, potassiumand some amounts of organic matter which makes water hard by getting dissolved in it.

5) Loss to Agricultural produce

Agriculture is badly affected by the rising pollution. The use of excessive pesticides, herbicides, and fertilisers is resulting in the falling productivity of the agricultural land as contaminated water by industrial effluents cannot be used for irrigation. Polluted water leads to stunted seeds growth, depriving farmers of bumper crop production which hampers the country's target of attaining self-sufficiency in food.

6) Loss of Export Revenue

Fishes found in India such as Hilsa, Rohu, Katla and prawns were once having the highest demand in Middle East. Due the increased water pollution in India these varieties of fishes got infected with disease causing microbes and chemicals. As a result several countries banned the import of these fishes which in return causes a severe loss of export revenue for India.

\section{Remedies to Curb Water Pollution:}

Water conservation in India is gaining pace. Central and state government are taking various steps to conserve water for sustainable future. Higher class protect themselves from water pollution by taking self-protective steps but the worst hit class is the weaker class which do not have adequate resources to save themselves. Some remedial actions must be taken to reduce this growing mammoth problem. Certain remedies to control water pollution are:

1) Management of Floating Pollution:

Plastic bottles and bags make water more toxic and hazardous. These pollutants should be properly managed and trapped. Strict measures should be taken to prevent these floating pollutants from reaching waterways to reduce the increasing menace of plastic pollution.

2) Treatment of Industrial water treatment:

Treatment of industrial waste include the removal of solid particles, reduction of organic waste material, use of safe chemicals to get rid of any leftover impurities or chemical contaminants This aids the safety of wastewater before it releases in the environment.

\section{3) Denitrification:}

It is an ecological process that is used to prevent the leaching of nitrates in the soil so that underground water in not contaminated with nutrients. Intercropping plant can help the excess nitrogen is converted into gas like nitrous oxide, nitrogen and nitrogen dioxide.

\section{4) Septic Tanks:}

Individual homesteads should use septic tanks. The sewage from the residential buildings should flow into to septic tanks where it is treated before water can flow out of tanks. First solid and liquid matters are separated and with the help of the biological process solid matter is degraded.

5) Minimum use of Detergents or Bleach:

People should use such products for cleaning which causes least damage to the environment. Use of effective amount of detergents and natural bleach products can serve a better alternative contaminated water will always end up by affecting the quality of water and this water is used by the people of the weaker sections of the society.

\section{Conclusion and Suggestions}

The findings of this article reviewed that in India there is lack of clean drinking water and sanitation. The water quality problems and incidence of various water-related diseases had economic impact on weaker households in the society in India. Infact it can be said that weaker sections of the society is most vulnerable to the impact of water pollution and the diseases caused by it. The water-related diseases, which mainly affected children, were diarrhoea, malaria, cholera, skin infections, etc.The number of days spent in illness, led to a loss of school days among children and loss of workdays and the consequent loss of income among adults.It put a big economic burden on the households due to the cost for treatment. These people spend the maximum share of their earning on the diseases. The low-income households spend a relatively higher proportion of their income to cope with water-related diseases, which further compounded their economic stress. This article unravel that the waste water treatment plants in India are either not adequate or they do not function well. Efforts are being made but not coping with the growing problem. Various measures taken to improve the agricultural yield and rapid industrialisation is also graving the situation in India. Rapid development measures taken by the government is leading to the increasing water diseases. The unplanned household practices like use of excessive water in the household chores and careless drainage further engraves the situation and affects the sustainability of the water.

The article suggests that a number of central and state government institutions and departments are functioning to monitor the quality of water. However, these efforts and investments in water supply and sanitation sector and measures taken by various pollution control boards still have not helped to improve health outcomes. The article suggests that there is a dire need to focus on the sustainability of water resources in the near future and also on the quality of 
water, as poor water quality can further affect the already dwindling water resources. An effective water policy is the need of the hour.

\section{References}

[1] "Annual Report of the Department of Agriculture Cooperation and Farmers' Welfare, 2016-17, based upon the 4th advance estimates for the year", athttp://agricoop.nic.in/sites/default/files/Annual_rpt_2 01617_E.pdf accesed on 14/12/2018

[2] A. Milanović, D. Milijašević, and J. Brankov, "Assessment of polluting effects and surface water quality using water pollution index: a case study of hydro-system Danube-Tisa-Danube, Serbia," Carpathian Journal of Earth and Environmental Sciences, vol. 6, no. 2, pp. 269-277, 2011.

[3] Rajni Kant and Keshav Kant, Water Pollution: Management, Control And Treatment, New Age International (P) Ltd, New Delhi, First Edition,2010.

[4] P. Mandal, R. Upadhyay, and A. Hasan, "Seasonal and spatial variation of Yamuna River water quality in Delhi, India," Environment Modellin\& Assessment, vol.170, no. 1-4, pp. 661-670, 2010.

[5] S. K. Agarwal, Water Pollution, APH Publishing Corporation, New Delhi, 2009.

[6] A.K. Dwivedi, Rahul Singh and Shashi. (2008) Grondwater Pollution: Causes and Impact, Indian Science Cruiser, 22(4): 29-33.

[7] P.K.Goel, Water Pollution: Causes, Effects and Control, New Age International, 2006.

[8] D. L. Saunders, and J. Kalff, 2001. Nitrogen retention in wetland, lakes and rivers. Hydroboil. 443.

[9] P. F. Blanchard and R.N. Lerch, 2000. Watershed vulnerability to losses of agricultural chemicals: Interactions of chemistry, hydrology, and land-use. Environmental Science and Technology.

[10] P. Martin, 1998. River pollution in India: An overview. Emp. News. XXII(52).

[11] S.C. Shukla, B.D. Tripathi, B.P. Mishra, and S.S. Chaturvedi, 1992. Physico-chemical and Bacteriological Properties of the Water of River Ganga at Ghazipur. Comp. Physiol. Ecol.

[12] M.A. House, "Water quality indices as indicators of ecosystem change," Environmental Modeling \& Assessment, vol. 15, 1990.

[13] H. Peavy, D. Rowe, and G. Tchobanoglous, "Environmental Engineering," 1986.

[14] K.D. Sharma, N. Lal, and R.D. Pathak, 1981. Water quality of sewage drains entering Yamuna at Agra. Indian J. Environ. Health.

[15] P. H. McGauhey, "Engineering Management of Water Quality," 1968.

[16] Annual Report of the Department of Water Conservation in India 2017-18. 